\title{
LETTER
}

\section{Ability of respiratory pulse pressure variation to predict fluid responsiveness in ARDS: still an unanswered question?}

\author{
Jihad Mallat*, Malcolm Lemyze and Didier Thevenin \\ See related research by Lakhal et al., http://ccforum.com/content/15/2/R85
}

We read with interest the study of Lakhal and colleagues [1] suggesting that respiratory pulse pressure variation (PPV) is not an accurate predictor of fluid responsiveness in patients with acute respiratory distress syndrome (ARDS) ventilated with low tidal volume (Vt). They stated that the poor performance of PPV is attributed to small changes in respiratory pleural pressure related to low Vt, such that PPV is low even in the case of marked cardiac preload dependency. These findings are not surprising since in this study [1] the mean static compliance was not very low $\left(40 \mathrm{cmH}_{2} \mathrm{O}\right)$; therefore, the percentage of transmission of alveolar pressure to the pleural space was not really altered. Thus, the ventilation with low Vt induced small variations in pleural and transpulmonary pressures.

It must be stressed, however, that patients with ARDS usually exhibit a severe decrease in lung compliance and high plateau pressure. Moreover, in ARDS patients ventilated with low Vt, application of relatively high levels of positive end expiratory pressure (between 10 and $15 \mathrm{cmH}_{2} \mathrm{O}$ ) is now recommended [2]. Consequently, respiratory changes in transpulmonary pressure should remain greater than normal, and in spite of reduced lung compliance, cyclic changes in intrathoracic pressure may still be high enough for PPV to predict fluid responsiveness [3].

The findings of Lakhal and colleagues [1] perhaps provide insufficient support for the assertion that PPV is unable to predict volume responsiveness in ARDS patients ventilated with low Vt. Additional studies in severe ARDS patients (compliance $<30 \quad \mathrm{cmH}_{2} \mathrm{O}$ ) are necessary to investigate whether or not PPV could be used in such cases.

\section{Authors' response: In ARDS, stiff lungs keep the pressure inside}

Stephan Ehrmann, Karim Lakhal and Thierry Boulain

We thank Dr Mallat and colleagues for giving us the opportunity to clarify some physiological points tackled in our study [1]. Their assertion that the mean static compliance was not very low(...); therefore, the percentage of transmission of alveolar pressure to the pleural space was not really altered' is in accordance with Jardin and colleagues findings [4] and their recalculated data [5]: the lower the lung compliance, the lower the alveolarto-pleural space transmission of pressure. By contrast, in the case of lower respiratory system compliance [Crs], the alveolar-to-pleural pressure transmission may be altered in quite different ways, depending on the causal mechanism: stiffer chest wall with no change in lung

*Correspondence: jihad_mallat@msn.com

Service de Réanimation Polyvalente, Centre hospitalier Dr Schaffner de Lens, 62307 Lens Cedex, France compliance leads to an increase in respiratory pleural pressure changes $\left[\Delta \mathrm{P}_{\text {pleural }}\right][6]$; and stiffer lungs lead to lower $\Delta \mathrm{P}_{\text {pleural }}$ (and lower respiratory variations in pulse pressure $\left.\left(\Delta_{\mathrm{RESP}} \mathrm{PP}\right)\right)$ for similar changes in alveolar pressure $\left(\Delta \mathrm{P}_{\text {alveolar }}\right)$. Importantly, the latter is the predominant mechanism of low Crs in ARDS [7].

In ARDS, two phenomena work in opposite directions for a given $V t[4,5]$ : (i) high $\mathrm{P}_{\text {alveolar }}$ swings increase $\Delta \mathrm{P}_{\text {pleural }}$ but (ii) high lung stiffness prevents $P_{\text {alveolar }}$ from being transmitted to the pleural space, therefore lowering $\Delta \mathrm{P}_{\text {pleural }}$ Confusion may arise when one takes the 'pressure transmission-reasoning shortcut' and thinks, as Dr Mallat and colleagues do, that the first phenomenon outweighs the second. Actually, basic physiological equations $\left(\Delta \mathrm{P}_{\text {pleural }}=\mathrm{Vt} /\right.$ Chest wall compliance $)$ remind us that $\Delta \mathrm{P}_{\text {pleural }}$ depends only on the $\mathrm{Vt}$ [5] and chest wall compliance [6] and not on lung compliance: the increase in $\mathrm{P}_{\text {alveolar }}$ (induced by decreased lung compliance) does not outweigh, but exactly compensates, the decrease in 
alveolar-to-pleural space transmission of pressure, as previously observed $[4,5]$. Further, other limitations for $\Delta_{\text {RESP }} \mathrm{PP}$ (heart-to-respiratory rate ratio or acute cor pulmonale [1]) would become even more prominent in a severe ARDS population, and further studies are likely to yield the same conclusion: $\Delta_{\text {RESP }} \mathrm{PP}$ fails to predict fluid responsiveness in ARDS.

\section{Abbreviations}

ARDS, acute respiratory distress syndrome; Crs, respiratory system compliance; $P_{\text {alveolar }}$ alveolar pressure; $P_{\text {pleural' }}$ pleural pressure; $P P V$, respiratory pulse pressure variation; Vt, tidal volume.

\section{Competing interests}

The authors declare that they have no competing interests.

Published: 10 June 2011

\section{References}

1. Lakhal K, Ehrmann S, Benzekri-Lefèvre D, Runge I, Legras A, Dequin PF, Mercier E, Wolf M, Régnier B, Boulain T: Respiratory pulse pressure variation fails to predict fluid responsiveness in acute respiratory distress syndrome. Crit Care 2011, 15:R85.
2. Briel M, Meade M, Mercat A, Brower RG, Talmor D, Walter SD, Slutsky AS, Pullenayegum E, Zhou Q, Cook D, Brochard L, Richard JC, Lamontagne F, Bhatnagar N, Stewart TE, Guyatt G: Higher vs lower positive end-expiratory pressure in patients with acute lung injury and acute respiratory distress syndrome: systematic review and meta-analysis. JAMA 2010, 303:865-873.

3. Teboul $\mathrm{J}$, Vieillard-Baron A: Clinical value of pulse pressure variations in ARDS: still an unresolved issue? Intensive Care Med 2005, 31:499-500.

4. Jardin F, Genevray B, Brun-Ney D, Bourdarias JP: Influence of lung and chest wall compliances on transmission of airway pressure to the pleural space in critically ill patients. Chest 1985, 88:653-658.

5. De Backer D, Heenen S, Piagnerelli M, Koch M, Vincent JL: Pulse pressure variations to predict fluid responsiveness: influence of tidal volume. Intensive Care Med 2005, 31:517-523.

6. Perel A, Pizov R, Cotev S: Systolic blood pressure variation is a sensitive indicator of hypovolemia in ventilated dogs subjected to graded hemorrhage. Anesthesiology 1987, 67:498-502.

7. Malhotra A: Low-tidal-volume ventilation in the acute respiratory distress syndrome. N Engl J Med 2007, 357:1113-1120.

doi:10.1186/cc10222

Cite this article as: Mallat J, et al:: Ability of respiratory pulse pressure variation to predict fluid responsiveness in ARDS: still an unanswered question? Critical Care 2011, 15:432. 